\title{
Evaluation of adult celiac disease from a tertiary reference center: a retrospective analysis
}

1. Tepecik Education and Research Hospital, Department of Gastroenterology, Yenisehir-Izmir/Turkey. 2. Tepecik Education and Research Hospital, Department of Internal Medicine, Yenisehir-Izmir/Turkey.

\begin{abstract}
SUMMARY
OBJECTIVE: It has been observed that celiac disease (CD) is not restricted to a single type characterized by diarrhea but also has atypical, asymptomatic (silent), and latent forms. The prevalence of this autoimmune disease, which affects approximately $1 \%$ of the world, is estimated to be around 3\%, including atypical and asymptomatic cases. In our study, we aimed to evaluate adult celiac patients.

METHODS: Between December 2008-2015, patients diagnosed with CD over the age of 18 years old were included in the study. Patients' symptoms at admission, frequency and type of anemia, transaminase levels, and celiac antibody positivity, and autoimmune diseases diagnosed at follow up were evaluated retrospectively.

RESULTS: Of 195 patients, 151 (77.4\%) were female. The mean age of the patients was $35.73 \pm 12.19$ years (range, 18-71 years). A hundred patients (51.3\%) had gastrointestinal symptoms. At the time of admission, 118 patients (60.5\%) had anemia, and 52 (26.7\%) had hypertransaminasemia. During the mean follow-up period of 58 months (36-120 months), 84 (43.1\%) of the patients presented at least one autoimmune disease, and this rate was $96.6 \%$ in individuals diagnosed above the age of 50 years.
\end{abstract}

CONCLUSION: In adult CD, resistant anemia, dyspepsia, and hypertransaminasemia are very common findings at the time of diagnosis, and the association with other autoimmune diseases, especially Hashimoto's thyroiditis, is high.

KEYWORDS: Celiac Disease. Adult. Autoimmune diseases. Anemia.

\section{INTRODUCTION}

Celiac disease (CD) is an immune-mediated persistent gluten intolerance that develops against gluten proteins such as barley, wheat, and rye in genetically predisposed individuals. Gluten proteins induce T-cell-associated inflammation in the small intestine and cause an autoimmune response to their own proteins, such as tissue transglutaminase. ${ }^{1}$ This causes villous atrophy, crypt hypertrophy, and intraepithelial lymphocytosis. With the developing technology and laboratory methods, it was observed that CD is not restricted to a single form characterized by diarrhea; atypical, asymptomatic (silent), and latent forms of the disease have also been discovered. In recent studies, it was observed that its incidence and prevalence have increased in both sexes and all age groups and that it is an autoimmune disease that affects approximately $1 \%$ of the world population. ${ }^{2}$ Since this ratio shows a biopsy-diagnosed population, it is suggested that the prevalence can be around 3\% when atypical and asymptomatic cases are included. ${ }^{3}$

Atypical and asymptomatic cases are frequently seen in patients diagnosed in adulthood. In the 
classical form seen in adults, only half of the cases have diarrhea, bloating, and abdominal discomfort. Diarrhea is sudden and is often chronic. There are no gastrointestinal symptoms in the atypical form. Hematological, psychiatric, endocrine, renal, neurological, rheumatologic, dermatological, and cardiovascular symptoms are common in the atypical form. ${ }^{4}$ However, most of these patients show severe mucosal damage and have a celiac-specific antibody pattern.

In our study, we aimed to perform a retrospective evaluation to determine their reason for admission, the prevalence of anemia, hypertransaminasemia at the time of diagnosis, and the frequency of autoimmune disease diagnosed in follow up or at the diagnosis in patients who were diagnosed with $\mathrm{CD}$ at our center over the age of 18 and were followed up for at least 3 years.

\section{MATERIAL AND METHODS}

Study group

Patients diagnosed with CD, with celiac antibodies positivity and duodenal biopsy between December 2008 and December 2015 were included in the study. CD was confirmed by the presence of partial, subtotal or total villous atrophy on duodenal biopsies, associated with increased intraepithelial lymphocyte counts and crypt hyperplasia, as defined by the modified Marsh criteria. ${ }^{3}$

\section{Inclusion Criteria}

Patients who had transaminase levels, complete blood count (CBC), anemia panel (iron, total iron-binding capacity, ferritin, B12, folic acid), thyroid function tests (free triiodothyronine (fT3), free thyroxine (fT4), thyroid-stimulating hormone (TSH), Anti-M antibodies, Anti-T antibodies) and celiac antibodies (anti-tissue transglutaminase immunoglobulin Ig A, anti-gliadin antibody IgA and IgG, anti-endomysial Ig A and G) at the time of diagnosis were included the study.

\section{Exclusion Criteria}

Patients diagnosed at under 18 years old, patients who had missing laboratory data and celiac antibodies at admission, patients whose duodenum and bulbous biopsies did not support CD were not included in the study.

The study was approved by the local ethical committee of the Tepecik Education and Research Hospital (No: 2019-0014).

\section{Evaluation of patients in the study group}

Symptoms of patients at admission, frequency, and type of anemia, transaminase levels, positivity, and levels of celiac antibodies and autoimmune diseases diagnosed during follow up were evaluated retrospectively.

\section{Statistical analysis}

Statistical analysis of the study was performed using SPSS 22.0 (IBM Statistical Package for Social Sciences software version 22). Continuous variables were expressed as mean \pm standard deviation (SD) or median (minimum-maximum) and categorical variables as percentages. The Chi-square test was used to compare categorical values between groups, and the Mann-Whitney U test was used to compare continuous variables between groups. $\mathrm{P}<0.05$ was considered statistically significant.

\section{RESULTS}

Demographic characteristics of patients and distribution by age groups

A total of 195 patients (151 females, 44 males) were included in the study. The mean age of the patients was $35.73 \pm 12.19$ years (range, $18-71$ years). A hundred of these patients (51.3\%) were referred to the gastroenterology outpatient clinic because of gastrointestinal (GIS) symptoms, 90 (46.2\%) for extra-GIS symptoms, and $5(2.6 \%)$ due to family history. The distribution of patients according to age groups and their reasons for referral to the gastroenterology outpatient clinic are summarized in Table 1. The distribution of the groups at admission are summarized in Figure 1a and $b$.

\section{Serology positivity at admission}

At the time of diagnosis, 185 (94.8\%) of the cases had anti-tissue transglutaminase IgA, 180 (92.4\%) had the anti-endomysium antibody, and 176 (90.2\%) had anti-gliadin antibody positivity.

Rates of anemia and hypertransaminasemia in patients at admission

A hundred and eighteen patients (60.5\%) had anemia (hemoglobin level; female: $<12$, male: $<13 \mathrm{~g} / \mathrm{L}$ ) at admission. A total of $53.3 \%$ of patients had iron deficiency anemia (IDA) (normal values of ferritin : 10-120 $\mathrm{ng} / \mathrm{mL}$, normal values of transferrin saturation: 20-40 $\mathrm{ug} / \mathrm{dL}$ ), 38.4\% had folic acid deficiency (normal values of folic acid: 4.6-18.7 pg/mL), 25\% had B12 deficiency (normal values of B12: 191-663 pg/mL) and 10.2\% had 
chronic disease anemia. Fifty-two patients (26.7\%) had hypertransaminasemia (AST or ALT level $>35 \mathrm{U} / \mathrm{L}$ ) at admission. The rates of anemia and hypertransaminasemia at the time of admission according to age groups are summarized in Figure 2a and b. In the subgroup analysis, no statistically significant difference was found between the groups in terms of anemia and hypertransaminasemia when the patients were classified as $<40$ and $\geq 40$ years old (Table 2 ).

\section{Rates of autoimmune diseases diagnosed} during follow-up

The mean follow-up period of 195 patients with CD diagnosed between December 2008 and December 2015 was 58 months (36-120 months). During the follow-up period, it was found that 84 patients (43.1\%) presented at least one autoimmune disease, and the most common was autoimmune thyroid disease (25.6\%) (Table 3). The total number of autoimmune diseases was 94 . The distribution of autoimmune thyroid diseases and other autoimmune diseases according to age groups is summarized in Figure $3 a$ and b. In the subgroup analysis, it was found that there was a statistically significant difference between the groups in terms of autoimmune thyroid diseases and other autoimmune diseases when the patients were classified as $<40$ and $\geq 40$ years old (Table 2 ).

\section{DISCUSSION}

As with other autoimmune diseases, CD is 2 to 3 times more common in females, affecting approximately $1 \%$ of the community. ${ }^{5}$ In our study, most patients were female (female/male; 2.9), similar to the literature. The prevalence of CD diagnosed with biopsy is reported between 0.4-0.9\% in our country. ${ }^{6,7}$ Developing diagnostic methods showed that the disease indeed resembles an iceberg and can be seen in individuals with atypical symptoms and in asymptomatic individuals, as well as in those with typical symptoms. In studies, especially in an adult group, it is found that the delays in diagnosis are quite frequent because of the frequency of atypical symptoms. ${ }^{4,8,9}$ In the study of Volta et al. ${ }^{10}, 86 \%$ of adult patients diagnosed in the last 5 years were found to be with non-classical and subclinical phenotypes. In the literature, we see that atypical and silent forms are more prominent than the classical symptoms in the cases diagnosed in adulthood in the last decades. ${ }^{4,10}$ In our study, we found that almost half of the patients presented with
extra-GIS symptoms. In addition, one-fifth of the cases referred for GIS symptoms were individuals with dyspeptic symptoms. In the subgroup analysis, more than $55 \%$ of patients, especially in the age groups of 30-50 and over 60 , were referred with extra-GIS symptoms. The majority of these cases consisted of patients with resistant anemia and hypertransaminasemia. This shows that screening tests, such as anti-tissue transglutaminase Ig A, are important in individuals with resistant anemia, dyspepsia, and hypertransaminasemia, especially in the adult age group without typical GIS symptoms.

TABLE 1. DISTRIBUTION OF PATIENTS ACCORDING TO AGE AND THEIR REASONS FOR REFERRAL.

\begin{tabular}{|c|c|c|}
\hline Diagnosis age & $n(\%)$ & Referral with GIS symptoms, \% \\
\hline $18-29 y$ & $65(33.3 \%)$ & $63 \%$ \\
\hline $30-39 y$ & $64(32.8 \%)$ & $40 \%$ \\
\hline $40-49 y$ & $36(18.5 \%)$ & $44 \%$ \\
\hline $50-59$ y & $21(10,8 \%)$ & $61 \%$ \\
\hline$\geq 60 y$ & $9(4.6 \%)$ & $42 \%$ \\
\hline
\end{tabular}

TABLE 2. THE RATES OF ANEMIA AND

HYPERTRANSAMINASEMIA AT DIAGNOSIS AND THYROID AND AUTOIMMUNE DISEASES IN FOLLOWUP AT PATIENTS $<40$ AND $\geq 40$ YEARS OLD.

\begin{tabular}{|c|c|c|c|}
\hline & $<40$ y $(\%)$ & $\geq 40$ y $(\%)$ & $\mathrm{p}$ \\
\hline Anemia & $62 \%$ & $57.6 \%$ & 0.327 \\
\hline Hypertransaminasemia & $26.4 \%$ & $27.3 \%$ & 0.510 \\
\hline Thyroid disease & $17.8 \%$ & $40.9 \%$ & 0.001 \\
\hline Autoimmune disease & $28.7 \%$ & $71.2 \%$ & 0.001 \\
\hline
\end{tabular}

TABLE 3. AUTOIMMUNE DISEASES AND RATES IN CELIAC PATIENTS.

\begin{tabular}{l|l} 
Autoimmune disease & $\mathrm{n}(\%)$ \\
\hline Hashimato's thyroiditis & $41(21 \%)$ \\
\hline Graves' disease & $9(4.6 \%)$ \\
\hline Sjogren & $8(4.1 \%)$ \\
\hline Primary biliary cirrhosis & $7(3.5 \%)$ \\
\hline Diabetes 1 & $5(2.5 \%)$ \\
\hline Seropositive rheumatoid arthritis & $5(2.5 \%)$ \\
\hline Dermatitis herpetiformis & $5(2.5 \%)$ \\
\hline Systemic lupus erythematosus & $4(2 \%)$ \\
\hline Ulcerative colitis & $3(1.5 \%)$ \\
\hline Autoimmune hepatitis & $3(1.5 \%)$ \\
\hline Polymyalgia rheumatica & $1(0.5 \%)$ \\
\hline Psoriasis vulgaris & $1(0.5 \%)$ \\
\hline Systemic sclerosis & $1(0.5 \%)$ \\
\hline Ankylosing spondylitis & $1(0.5 \%)$ \\
\hline
\end{tabular}


$\mathrm{CD}$ is also highly associated with other autoimmune diseases. ${ }^{8,11-14}$ In the large patient cohort study by Grode et al. ${ }^{8}$, the disease was associated with 31 different autoimmune comorbid diseases. Studies have shown that $\mathrm{CD}$ is more common in patients with type 1 Diabetes Mellitus, thyroiditis, and psoriasis because of shared immune-associated pathogenesis. ${ }^{11,14}$ The association of endocrine and dermatological events is more common in the diagnosis of CD in adulthood. The most common concomitant autoimmune disease was Hashimato's thyroiditis..$^{15}$ In the literature, the association of thyroid diseases with CD was reported as $2-24.3 \%{ }^{4,11,12}$ The reason for this prevalence appears to be multi genetic loci such as HLA-DR3, HLA-DQ2,

FIGURE 1. SYMPTOM DISTRIBUTION OF PATIENTS DIAGNOSED WITH A) EXTRA-GIS SYMPTOMS B) GIS SYMPTOMS.

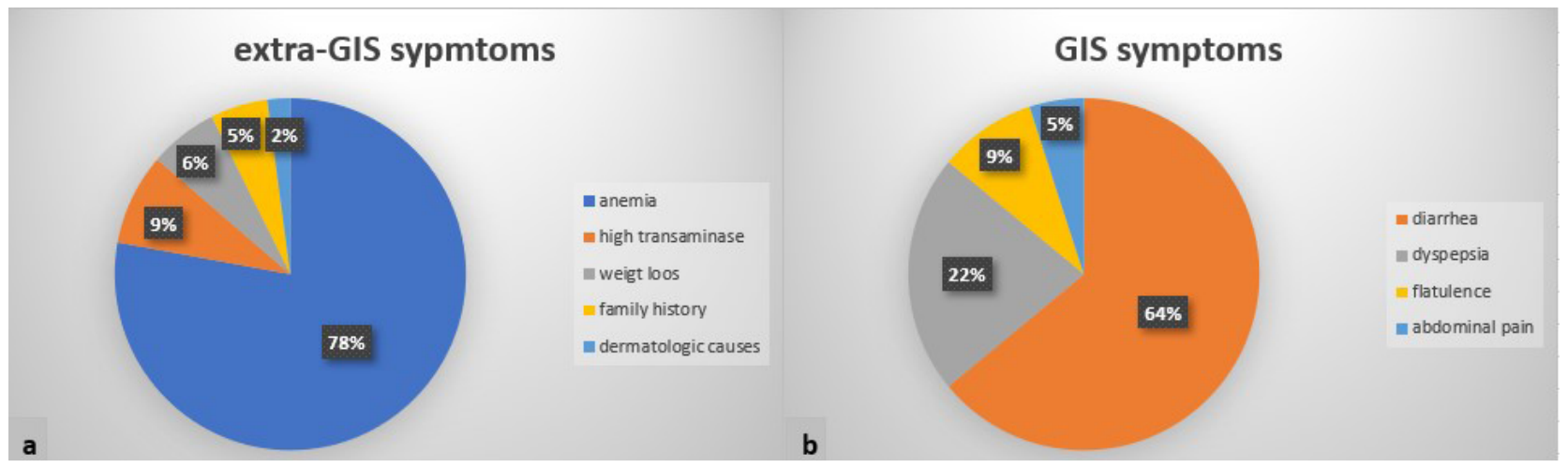

FIGURE 2. A) DISTRIBUTION OF ANEMIA RATES ACCORDING TO AGE GROUPS B) DISTRIBUTION OF HYPERTRANSAMINASEMIA ACCORDING TO AGE GROUPS.

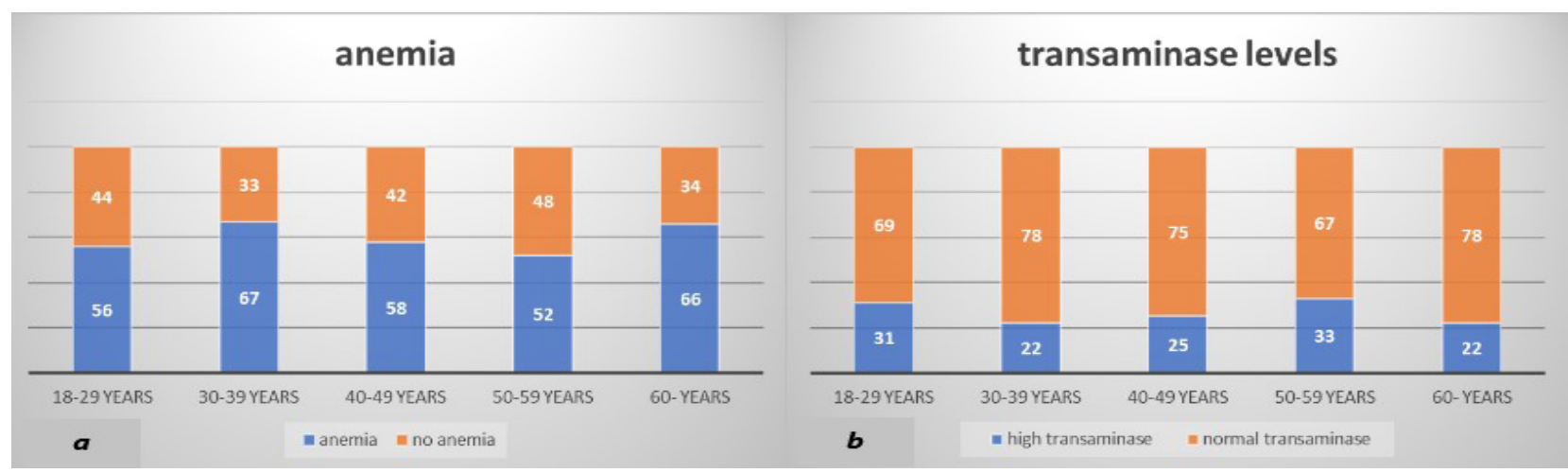

FIGURE 3. A) DISTRIBUTION OF PATIENTS WITH AUTOIMMUNE THYROID DISEASES ACCORDING TO AGE GROUPS DURING FOLLOW-UP B) DISTRIBUTION OF PATIENTS DIAGNOSED WITH AUTOIMMUNE DISEASE ACCORDING TO AGE GROUPS DURING FOLLOW-UP.

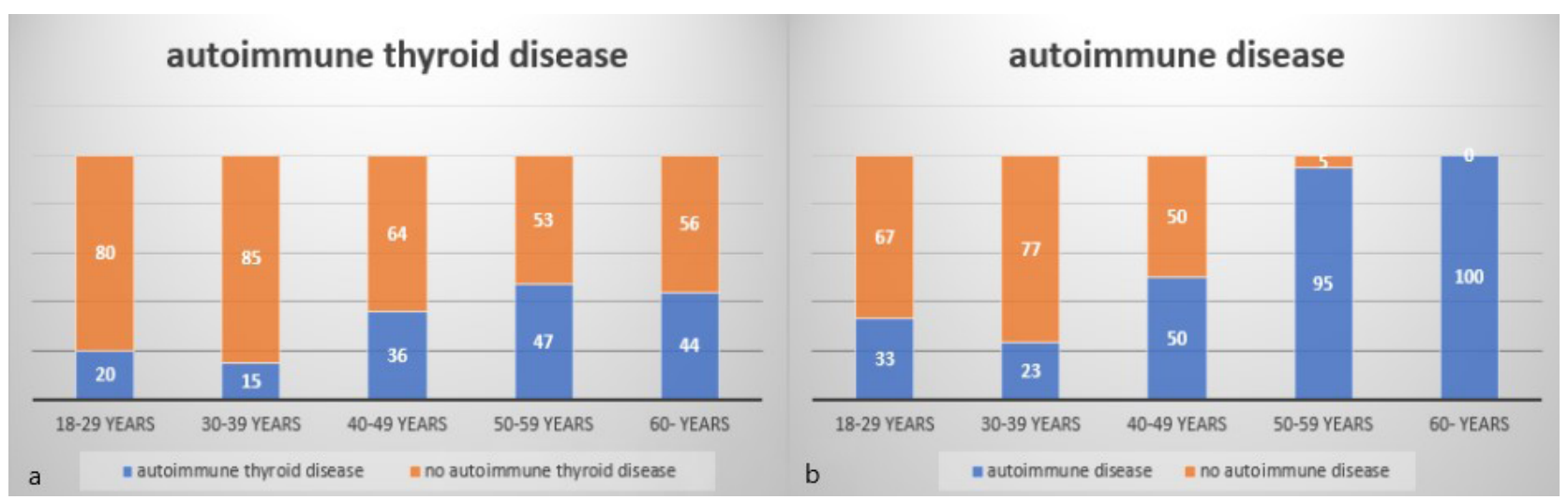


common to autoimmune diseases. ${ }^{16}$ In our study, autoimmune diseases were observed in $43.1 \%$ of the cases, and autoimmune thyroid diseases were the most common with $25.6 \%$, due to the mean follow-up period of 58 months after diagnosis. In the subgroup analysis, it was determined that there was a statistically significant difference in autoimmune disease $(28.7 \%$ versus $71.2 \% ; \mathrm{p}<0.001)$ and autoimmune thyroid diseases $(17.8 \%$ versus $40.9 \% ; p<0.001)$ in individuals between $<40$ and $\geq 40$ years old.

In addition, it was found that anemia is quite a common finding, especially in patients with CD. In studies, the prevalence of anemia is $12-85 \%$ in patients with $\mathrm{CD}^{4,17,18}$ In particular, IDA is quite common due to the pathophysiology of the disease. In one meta-analysis, one of 31 patients with IDA was reported to have CD. ${ }^{19}$ IDA was observed in $26 \%$, folate deficiency in $12 \%$, B12 deficiency in $5 \%$ of 405 patients according to Harper et al.'s ${ }^{18}$ study. IDA and folic acid deficiency associated primarily with the effect of CD on the proximal small bowel mucosa are common findings, and B12 deficiency absorbed from terminal ileum is also another cause. Several hypotheses have tried to explain B12 deficiency in CD. Although it cannot be fully elucidated, one of the probabilities is the association with autoimmune gastric atrophy, which is another autoimmune disease. This may also be due to the disruption of B12 and salivary R protein (haptocorrin) complexes due to concomitant pancreatic insufficiency and associated disruption of pancreatic proteases. ${ }^{20}$ Another possibility is that villous involvement in celiac disease is not limited to the proximal small bowel but also exists in the ileum. ${ }^{21}$ In studies, B12 deficiency was reported in 11-41\% of CD., ${ }^{4,21}$ In our study, we found that more than half of the patients were anemic (60.1\%) in all age groups at the time of admission. In accordance with the literature, it was observed that IDA (53.3\%) and folic acid deficiency (38.4\%) were the most frequent, and B12 deficiency $(25.6 \%)$ was found in one-fourth of the cases. In the subgroup analysis, the rates of anemia were found to be similar in individuals $<40$ and $\geq 40$ years old $(62 \%$ versus $57.6 \%$; $p=0.327$ ).

Hypertransaminasemia is a very common finding in treatment-naive patients and is seen in approximately $40 \%$ of adult cases and $60 \%$ of pediatric cases at the time of diagnosis. ${ }^{22}$ In addition, approximately 9\% of individuals with chronic unexplained hypertransaminasemia can have clinical or serological evidence of $\mathrm{CD}^{23}$ Studies have shown that the risk of late-stage liver disease is 2 to 6 times greater, and the risk of death due to liver cirrhosis is 8 times higher than in the normal population. ${ }^{24}$ However, the relationship between the disease and liver damage cannot be clearly identified; in individuals susceptible, following gluten exposure to the abnormal intestinal permeability due to a predisposition of common genetic factors, such as HLA associated with autoimmunity, cytokines, autoantibodies, and various biological mediators are thought to play a role in the pathogenesis. ${ }^{25}$ In our study, close to one-fourth of the cases (26.7\%) had hypertransaminasemia at the admission. In addition, 2 patients (1\%) diagnosed with cirrhosis were also diagnosed with CD based on the results of celiac antibodies and duodenal biopsy, although they were asymptomatic. In the subgroup analysis, hypertransaminasemia was found to be similar in individuals < 40 and $\geq 40$ years old ( $26.4 \%$ versus $27.3 \%$; $p=0.51$ ).

Since our study is a retrospective study, it has some limitations. First, there is a lack of data for many patients regarding the duration of symptoms in the past during their referral to the outpatient clinic. This prevents us from having data about the delay of the diagnosis. Secondly, due to the lack of detailed data on the other causes of anemia, such as diet, menstrual cycle-related excessive bleeding, anemia rates reflect the overall rates of anemia seen in $\mathrm{CD}$ at the time of diagnosis. Thirdly, it is useful to note that the cases with hypertransaminasemia at the time of diagnosis had not only CD but should also be associated with other diseases that cause hypertransaminasemia, such as hypothyroidism, as well as concomitant autoimmune liver disease.

\section{CONCLUSIONS}

In conclusion, $\mathrm{CD}$ patients may not present typical symptoms and signs in adulthood. Especially in individuals with unexplained resistant anemia, dyspepsia, and hypertransaminasemia, screening tests for CD are important. The disease is frequently associated with other autoimmune diseases due to its autoimmune character. We think that, especially in cases diagnosed above the age of 40 years, it is necessary to conduct an examination and screening tests, especially for a second comorbid such as endocrine and rheumatic autoimmune diseases.

\section{Conflict of interest}

None. 


\section{Authors' Contribution}

Concept: OBB. Design: OBB. Supervision: FT. Materials: OBB, FT. Data collection and processing:
FT. Analysis and interpretation: OBB, FT. Literature search: OBB. Writing: OBB. Critical reviews: OBB.

\section{RESUMO}

OBJETIVOS: Observou-se que a doença celíaca (DC) não se restringe a um único tipo caracterizado por diarreia, mas também tem formas atípicas, assintomáticas (silenciosas) e latentes. Estima-se que a prevalência desta doença autoimune, que afeta aproximadamente $1 \%$ da população do mundo, seja em torno de 3\%, incluindo casos atípicos e assintomáticos. Em nosso estudo, objetivou-se avaliar pacientes celíacos adultos.

MÉTODOS: Entre dezembro de 2008 e 2015, pacientes diagnosticados como DC com idade acima de 18 anos foram incluídos no estudo. Os sintomas dos pacientes na admissão, frequência e tipo de anemia, níveis de transaminases e positividade de anticorpos celíacos e doenças autoimunes diagnosticadas no seguimento foram avaliados retrospectivamente.

RESULTADOS: Dos 195 pacientes, 151 (77,4\%) eram do sexo feminino. A média de idade dos pacientes foi de 35,73.12,19 anos (variação de 18 a 71 anos). Cem pacientes (51,3\%) foram encaminhados com sintomas gastrointestinais. No momento da internação, 118 pacientes (60,5\%) apresentavam anemia e 52 (26,7\%) apresentavam hipertransaminemia. Durante o período médio de acompanhamento de 58 meses (36-120 meses), 84 (43,1\%) pacientes estavam acompanhados por pelo menos uma doença autoimune, e essa taxa foi de $96,6 \%$ em indivíduos diagnosticados acima dos 50 anos de idade.

CONCLUSÃO: No adulto DC, anemia resistente, dispepsia e hipertransaminasemia são achados muito comuns no momento do diagnóstico e a associação com outras doenças autoimunes, especialmente tireoidite de Hashimoto, é alta.

PALAVRAS-CHAVE: Doença celíaca. Adulto. Doenças autoimunes. Anemia.

\section{REFERENCES}

1. Sollid LM. Coeliac disease: dissecting a complex inflammatory disorder. Nat Rev Immunol. 2002;2(9):647-55.

2. West J, Fleming KM, Tata LJ, Card TR, Crooks C). Incidence and prevalence of celiac disease and dermatitis herpetiformis in the UK over two decades: population-based study. Am J Gastroenterol. 2014;109(5):757-68.

3. Mooney PD, Leeds JS, Libzo N, Sidhu R, Evans KE, Hall El, et al. Case-finding for coeliac disease in secondary care: a prospective multicentre UK study. Dig Liver Dis. 2014;46(1):32-5.

4. Paez MA, Gramelspacher AM, Sinacore J, Winterfield L, Venu M. Delay in diagnosis of celiac disease in patients without gastrointestinal complaints. Am J Med. 2017;130(11):1318-23.

5. Bardella MT, Fredella C, Saladino V, Trovato C, Cesana BM, Quatrini M, et al. Gluten intolerance: gender- and age-related differences in symptoms. Scand | Gastroenterol. 2005;40(1):15-9.

6. Çaltepe G. The hidden danger: silent celiac disease. Turk | Gastroenterol. 2018;29(5):530-1.

7. Sezgin O, Sarıtaş B, Aydın I, Şaşmaz T, Linke ES. Celiac disease prevalence in Turkey: a population based cross-sectional study. Acta Med Mediterr. 2016;32:463-71.

8. Grode L, Bech BH, Jensen TM, Humaidan P, Agerholm IE, Plana-Ripoll O, et al. Prevalence, incidence, and autoimmune comorbidities of celiac disease: a nation-wide, population-based study in Denmark from 1977 to 2016. Eur J Gastroenterol Hepatol. 2018;30(1):83-91.

9. Zipser RD, Patel S, Yahya KZ, Baisch DW, Monarch E. Presentations of adult celiac disease in a nationwide patient support group. Dig Dis Sci. 2003:48(4):761-4.

10. Volta U, Caio G, Stanghellini V, De Giorgio R. The changing clinical profile of celiac disease: a 15-year experience (1998-2012) in an Italian referral center. BMC Gastroenterol. 2014;14:194.

11. Bibbò S, Pes GM, Usai-Satta P, Salis R, Soro S, Quarta Colosso BM, et al. Chronic autoimmune disorders are increased in coeliac disease: a case-control study. Medicine (Baltimore). 2017;96(47):e8562.

12. Collin P, Salmi |, Hällström O, Reunala T, Pasternack A. Autoimmune thyroid disorders and coeliac disease. Eur J Endocrinol. 1994;130(2):137-40.

13. Kalkan C., Karakaya F, Soykan I. Similarities and differences between older and young adult patients with celiac disease. Geriatr Gerontol Int. 2017;17(11):2060-7.
14. Lundin KE, Wijmenga C. Coeliac disease and autoimmune disease-genetic overlap and screening. Nat Rev Gastroenterol Hepatol. 2015;12(9):507-15.

15. Demirezer Bolat A, Akin FE, Tahtaci M, Tayfur Yürekli Ö, Köseoglu H, Erten S, et al. Risk factors for polyautoimmunity among patients with celiac disease: a cross-sectional survey. Digestion. 2015;92(4):185-91.

16. Houlston RS, Tomlinson IP, Ford D, Seal S, Marossy AM, Ferguson A, et al. Linkage analysis of candidate regions for coeliac disease genes. Hum Mol Genet. 1997;6(8):1335-9.

17. Bottaro G, Cataldo F, Rotolo N, Spina M, Corazza GR. The clinical pattern of subclinical/silent celiac disease: an analysis on 1026 consecutive cases. Am J Gastroenterol. 1999;94(3):691-6.

18. Harper JW, Holleran SF, Ramakrishnan R, Bhagat G, Green PH. Anemia in celiac disease is multifactorial in etiology. Am J Hematol. 2007;82(11):996-1000.

19. Mahadev S, Laszkowska M, Sundström J, Björkholm M, Lebwohl B, Green $\mathrm{PHR}$, et al. Prevalence of celiac disease in patients with iron deficiency anemia: a systematic review with meta-analysis. Gastroenterology. 2018;155(2):374-82.

20. Allen RH, Seetharam B, Allen NC, Podell ER, Alpers DH. Correction of cobalamin malabsorption in pancreatic insufficiency with a cobalamin analogue that binds with high affinity to $R$ protein but not to intrinsic factor. In vivo evidence that a failure to partially degrade $\mathrm{R}$ protein is responsible for cobalamin malabsorption in pancreatic insufficiency. J Clin Invest. 1978;61(6):1628-34

21. Dickey W. Low serum vitamin B12 is common in coeliac disease and is not due to autoimmune gastritis. Eur J Gastroenterol Hepatol. 2002;14(4):425-7.

22. Rubio-Tapia A, Murray JA. Liver involvement in celiac disease. Minerva Med. 2008;99(6):595-604.

23. Bardella MT, Vecchi M, Conte D, Del Ninno E, Fraquelli M, Pacchetti S, et al. Chronic unexplained hypertransaminasemia may be caused by occult celiac disease. Hepatology. 1999;29(3):654-7.

24. Ludvigsson JF, Elfström P, Broomé U, Ekbom A, Montgomery SM. Celiac disease and risk of liver disease: a general population-based study. Clin Gastroenterol Hepatol. 2007;5(1):63-9.

25. Peláez-Luna M, Schmulson M, Robles-Díaz G. Intestinal involvement is not sufficient to explain hypertransaminasemia in celiac disease? Med Hypotheses. 2005;65(5):937-41. 